\section{Misconceptions of Sixth Grade Secondary School Students on Fractions}

\author{
Feyza Aliustaoğlua ${ }^{a}{ }^{*}$, Abdulkadir Tunab ${ }^{b}$ Abdullah Çağrı Biber ${ }^{c}$
}

$\begin{array}{ll}\text { Received: } & 11 \text { April } 2018 \\ \text { Revised: } & 18 \text { May } 2018 \\ \text { Accepted: } \quad & \text { 07 June } 2018 \\ \text { ISSN: } 1307-9298 \\ \text { Copyright (C) IEJEE } \\ \text { www.iejee.com }\end{array}$

DOI: 10.26822/iejee.2018541308

\begin{abstract}
The purpose of this study is to determine the misconceptions of 6th-grade secondary school students in terms of part-whole relation in fractions, representation of fractions on the number line, comparison of fractions and operations in fractions. The sample of this study is composed of 104 students who are being educated in 6th-grade of five secondary schools in 2017-2018 teaching year in a province which takes place in the north part of Turkey. Fractional information test, which consists of 5 open-ended questions developed by researchers, was used as data collection tool. The data of the study were analyzed using the content analysis method and in this method frequency/percentage tables were used. By examining the explanations that the students have made, the incorrect answers are divided into categories, and the misconceptions in each question are presented separately. As a result of the study, it has been seen that students have misconceptions in terms of parts-whole relation in fractions, representation of fractions on the number line, comparison of fractions and operations in fractions.
\end{abstract}

Keywords: Mathematics education, misconceptions, fractions.

\section{Introduction}

Fraction is a fundamental subject which has critical importance for students and essential for algebra and many advanced mathematics topics (Van De Walle, Karp, \& Bay-Williams, 2012). This subject is the basis of many subjects such as decimals, rational numbers, rate-ratio in the mathematics curriculum (Arslan-KIlcan, 2006). It is one of the main topics in the numbers and operations learning area in the secondary school mathematics curriculum at all grade levels (MoNE, 2013). Fraction concept is more difficult for students than many of the topics in the curriculum and it is stated that it is very difficult for students to understand fractions as numbers and how to do operations with these numbers (Olkun \& Toluk-Uçar, 2007). The results of the NAEP test also show that students' understanding of fraction concept is inadequate (NAEP, 2007). The weakness of students' understanding of fraction leads to difficulties in many areas; such as decimals, percentage,rate-ratio, measuring fractions and using them in algebra (NMP, 2008).

Misconceptions are defined as interpretations according to their own understanding of concepts that students have difficulty in understanding and the difference in the point of students' view from the points of scientists' view (Mayer, 1987). In other words, misconceptions are the difference of basic perception between the students and experts and students' understanding which produce mistakes in a systematic way (Smith, diSessa, \& Roschelle, 1993). Looking at this definition, it is seen that error and misconception are different terms. Mistakes that students make systematically are different from simple calculation errors and misconceptions are a form of perception that causes to make mistakes in a very systematic way, rather than a simple mistake (Zembat, 2008). If mistakes made by the students are considered as the image on the surface, misconceptions are the source of this vision (Nesher, 1987). When the literature is examined, it is seen that the students at all levels of education have many misconceptions about fractions (Alacaci, 2012; Biber, Tuna, \& Aktaş, 2013; Hansen, 2014; Işık \& Kar, 2012; Kocaoğlu \& Yenilmez, 2010; Ojose, 2015; Okur \& Çakmak Gürel, 2016; Önal \&Yorulmaz, 2017; Pesen, 2007; Pesen, 2008; Soylu \& Soylu, 2005; Yetim \& Alkan 2010; Yılmaz \& Yenilmez, 2007; Taşkın \& Yıldız, 2011). It is seen that a considerable part of these misconceptions derives from the generalizations of previous learning to the fractions (Alacaci, 2014). Students build new concepts by using their previous knowledge such as natural numbers. Based on their knowledge of natural numbers they think that numerator and denominator are separate values, they can not imagine that the pieces of fraction must be equal to one another, they rank fractions by looking at the numbers at numerator and denominator rather than considering the whole fraction, they use the rules of operations which they used in natural numbers at fractions (Van De Walle, Karp, \& Bay-Williams, 2012). It has been pointed out that the teaching of fractions without considering the experiences of the students and conceptual substructure, and the rapid passing through the abstract symbols lead to the misconceptions (Bezuk \& Bieck, 1993).

When we look at the literature, we encounter different types of misconceptions about fractions. The first thing to pay attention to the teaching of fractions is the idea that whole fractional pieces must be equal in size to each other (Van De Walle, Karp, \& Bay-Williams, 2012). Several studies show that there are misconceptions related to all pieces of fractions being not equal to each other (Alacaci, 2014; Demiri, 2013; Haser \& Ubuz, 2002; Karaağaç \& Köse, 2015; Kocaoğlu \& Yenilmez, 2010; Okur \& Çakmak Gürel, 2016; Pesen, 2007; Reys et al., 1998). The reason for this misconception is stated as passing to a demonstration of fractions with symbols before forming a conceptual background (for example by giving a

\footnotetext{
a,* Corresponding Author: Kastamonu University, Faculty of Education, Department of Mathematics and Science Education, Kastamonu, Turkey. E-mail: fdemirci@kastamonu.edu.tr

b Kastamonu University, Faculty of Education, Department of Mathematics and Science Education, Kastamonu, Turkey. E-mail: atuna@kastamonu.edu.tr

Kastamonu University, Faculty of Education, Department of Mathematics and Science Education, Kastamonu, Turkey.

E-mail: acbiber@kastamonu.edu.tr
} 
symbolic representation $2 / 5$ before telling exactly what is the meaning of the $2 / 5$ fraction by showing the concrete models) (Alacaci, 2014).

Another misconception about fractions relates to the representation of fractions on the number line. Many researchers emphasize the necessity of using number lines in the teaching of fractions (Clarke, Roche, \& Mitchell, 2008; Flores, Samson, \& Yanik, 2006; Middleton, Van den Heuvel-Panhuizen, \& Shew, 1998; Usiskin, 2007). The number line is a useful model to better understand which fraction is smaller or bigger and to reinforce that there is always another fraction between two fractions (Van De Walle, Karp, \& Bay-Williams, 2012). Related to the representation of fractions on number line; it is seen that there are misconceptions about how to divide the whole into pieces, how many of them will be taken, and how to determine the unit in simple and compound fractions (Bright, Behr, Post and Wachsmuth, 1988; Okur \& Çakmak Gürel, 2016; Önal \& Yorulmaz, 2017; Pesen, 2008; Yanik et al., 2008; Yetim \& Alkan, 2010).

When we look at the misconceptions about the ranking of fractions, it is seen that there are misconceptions based on ranking by looking at only numerator or denominator and the assumption that if the numbers at numerator and denominator is bigger, the fraction is bigger compared to the other. (Biber, Tuna, \& Aktaş, 2013; Hansen, 2014; Hart et al., 1980; Haser \& Ubuz, 2002; Mack, 1990; McLeod \& Newmarch, 2006; Okur \& Çakmak Gürel, 2016; Önal \& Yorulmaz, 2017). It is stated that this misconception is due to focusing on a single component instead of the searching relationship between numerator and denominator and thinking fractions as natural numbers (Alacaci, 2014).

It is stated that the misconceptions in operations on fractions are derived from considering fractions as integers, teaching operations in fractions without understanding the fractions and equivalent fractions exactly and based on only rules without the conceptual infrastructure being explained (Alacaci, 2014). There are also researches on the misconceptions of students about operations in fractions (Biber, Tuna, \& Aktaş, 2013; Crouse \& Sloyer, 1987; Haser \& Ubuz, 2002; McLeod \& Newmarch, 2006; Ojose, 2015; Okur \& Çakmak Gürel, 2016; Önal \& Yorulmaz, 2017; Soylu \& Soylu, 2005; Stafylidou \& Vosniadou, 2004; Vamvakoussi \& Vosniadou 2004). Students learn to do operations on fractions routinely every year, but they forget how to do this later because of doing it by memorizing formulas and algorithms (Şiap \& Duru, 2004).

It is thought that it is important to be aware of the misconceptions of the students on this issue so that the teaching of fractions can be done more effectively. In addition, it is believed that the identification of the misconceptions in this context is important in terms of re-proving the misconceptions that exist in the literature. It can be said that the presentation of the students' misconceptions in this way can enable the teachers to plan the teaching by taking into account these misconceptions and thus to realize the learning at the conceptual level. In addition, in other studies students were asked to solve only the questions given. However in this research by using open-ended questions students were also asked to explain how they solve each question as well as solving them. It is thought that this research will provide detailed information about students' thinking. On the other hand, when we looked at the literature, it was seen that the studies about the misconceptions in the fractions are generally at the primary school level. In this study, misconceptions about the fractions of the 6 th-grade students were determined. It can be said that the research is different from the researches in the literature due to the reasons mentioned.

\section{Purpose of The Research}

The purpose of this research is to determine the misconceptions of 6th-grade students regarding part-whole relations in fractions, representation of fractions on the number line, ranking of fractions and operations in fractions.

\section{Problem of The Research}

Problem of the research is "What are the misconceptions of the 6th class students about fractions?" The following sub-problems were searched for this research problem.

1. What are the misconceptions of 6th-grade students regarding the part-whole relations in fractions?

2. What are the misconceptions of 6th-grade students regarding the representation of fractions on the number line?

3. What are the misconceptions of 6th-grade students regarding the ranking of fractions?

4. What are the misconceptions of 6th-grade students regarding the operations in fractions?

\section{Methodology}

\section{Research Model}

The aim of the research is to reveal the misconceptions of the 6th-grade students about the fractions and to get in-depth knowledge about the misconceptions of this concept. In this context, the case study method of qualitative research methods was used in the research. The case study method is defined as the determination of the investigation' status and in-depth examination of the situation (Bogdan \& Biklen, 2007, p. 59). This method is the preferred method when it is necessary to examine the situation as a whole and in a comprehensive way (Feagin, Orum, \& Sjoberg, 1991). In this study, the case study method was used in order to determine the students' misconceptions about the fractions and to investigate these misconceptions by depth.

\section{Data Collection Tools}

In the study, 5 open-ended questions were used as a data collection tool in order to investigate the students' learning of part-whole relation in fractions, representation of fractions on the number line, rank of fractions and operations in fractions. In two questions, the students were asked to determine which of the statements given are correct/incorrect and also to express the reasons why they chosed correct or incorrect. Similarly, students were asked to explain how they responded to the questions about ranking fractions from small to large. This situation was expressed to the students during the application and it was emphasized that they should make the necessary explanations. In this way, it was tried to prevent giving right answer to the question with luck. The answers and explanations given by the students were examined and it was determined whether they have misconceptions or not. Prior to the preparation of the questions, the studies in this area in the literature were examined and the misconceptions were determined. More than one question was asked about each misconception, so it was examined whether the students had misconceptions in both similar questions. While preparing the questions, researchers benefited from the questions that McLeod and Newmarch 
(2006), Yanik et al. (2008), Loc, Tong and Chau (2017) had used in their studies. Then, two mathematics educators' opinions were taken about the prepared questions. According to expert opinions, one item in the first question was removed because it could lead to misunderstandings of the students. In this way, the test was ready for implementation. The first question in the test was about the parts-whole relation of fractions, the second one is about display fractions on the number line, the third one is about ranking of fractions, the fourth one is about making summation operation by using modeling and the last one is about summation, multiplication and division operations in fractions.

\section{Sample}

The sample of this study was composed of 104 students who are being educated in 6th-grade of five secondary schools in a province which takes place in the north part of Turkey. The application was made in the first semester of the 2017-2018 academic year. A simple random sampling method was used in this study. In this sampling method, the probability of selecting each group is equal to each other (Çepni, 2010). The distribution of students participating in the study by gender was shown in Table 1.

Table 1. Distribution of students participating in the study by gender

\begin{tabular}{|c|c|c|}
\hline Gender & Frequency & Percentage \\
\hline Female & 59 & 56.73 \\
\hline Male & 45 & 43.27 \\
\hline Total & 104 & 100 \\
\hline
\end{tabular}

According to Table 1, it was seen that $56.73 \%$ of the students who participated in the test were female and $43.27 \%$ were male.

\section{Analysis of Data}

The answer sheets of students were coded as S1, S2, S3, ..., S104. The answers of the students were examined in three categories as right, wrong and empty for each question. The students' misconceptions were determined by looking at the answers they gave and explanations they made. The misconceptions were divided into categories by the researchers based on the answers given by the students after the examination of all the papers, and sample student answers for each misconception were also presented in tables. In the analysis of the data, each student response was coded by all researchers independently. The inter-coder reliability was determined by the kappa coefficient of Fleiss and was found 0,80. According to the classification made by Fleiss, Kappa value is considered to be a perfect consistency when it is 0,75 and above this value (Fleiss, 1981). When this classification was taken into consideration, it was seen that the percentage of consistency is appropriate. Also, in the event of disagreement, the answers were re-examined and a common decision was reached. Descriptive statistical techniques (frequency/percentage) were used in the analysis of the data obtained from the test. Sample misconceptions for each question were also presented and shown in the tables.

\section{Results}

In this section, analyzes of the students' responses to the questions were given. The analyzes were done separately for each question, as the different acquisitions of fractions were taken into account. Each one of the first three questions in the test was directed to a subproblem, and the fourth and fifth questions were directed to a single subproblem. Thus, answers were sought for four sub-problems by using the total of five questions.

\section{Results related to first sub-problem}

The first question was about the part-whole relationship in fractions. The students were asked to evaluate the given statements as true or false and to make necessary explanations. The first question of the test was shown in Figure 1.

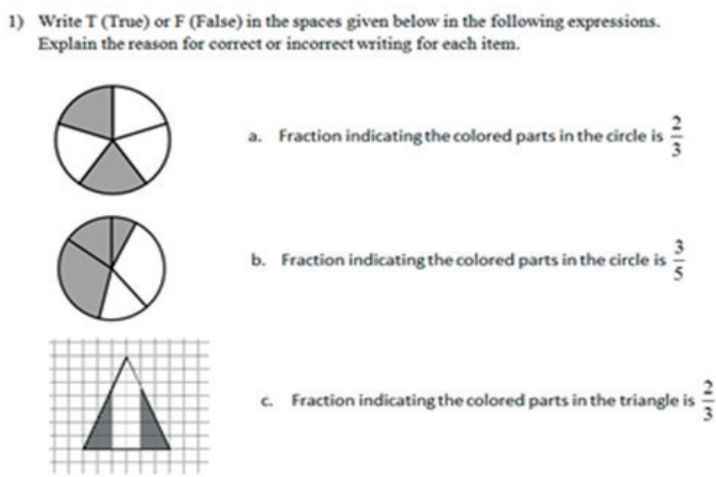

Figure 1. The first question of the fraction information test

The distribution of the students' responses to the first question was presented in Table 2 .

Table 2. Distribution of students' responses to the first question

\begin{tabular}{crrrrrr}
\hline \multirow{2}{*}{ Evaluation } & $\mathrm{a}$ & \multicolumn{3}{c}{$\mathrm{b}$} & \multicolumn{3}{c}{$\mathrm{c}$} \\
\cline { 2 - 7 } & $f$ & $\%$ & $f$ & $\%$ & $f$ & $\%$ \\
\hline True & 100 & 96.15 & 68 & 65.38 & 57 & 54.81 \\
\hline False & 4 & 3.85 & 36 & 34.62 & 45 & 43.27 \\
\hline Empty & - & - & - & - & 2 & 1.92 \\
\hline Total & 104 & 100 & 104 & 100 & 104 & 100 \\
\hline
\end{tabular}

According to Table 2, it was seen that the percentage of students who answered incorrectly to item a that all pieces are equal to each other is very little (3.85\%). However, the percentages of students who answered incorrectly to item $b$ and $c$ that all pieces aren't equal to each other were quite high $(34.62 \%, 43.27 \%)$. In addition, it was seen that the percentage of wrong answers to the triangular shape is higher than the circular shape. The misconceptions of the students in the first question were given in Table 3 in categories.

Table 3. Misconceptions in the first question and sample student answers

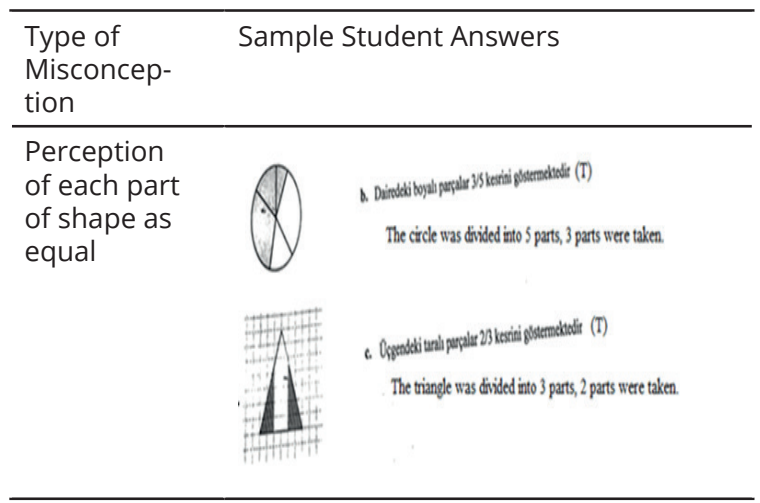


Looking at the explanations made by the students, it was seen that in fractions, they couldn't think that all the pieces have to be equal, they only focused on how many total pieces are there and how many are dyed.

\section{Results Related to Second Sub-problem}

The second question related to the representation of fractions on the number line. Students were asked to show the simple and compound fractions given on the number line. Here, the number line was limited to 0 and 6 points, and it was examined whether or not the students pay attention to the unit of the fraction when they show the fraction.

Misconceptions were identified by asking two questions with the same difficulty level for simple and compound fractions and by analyzing the answers of the students in both questions in parallel. The second question of the test was shown in Figure 2.

2) a. Show the fraction $\frac{2}{3}$ on the number line below.

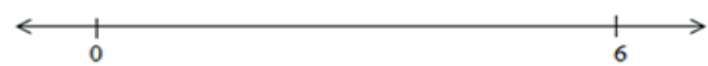

b. Show the fraction $\frac{9}{4}$ on the number line below.

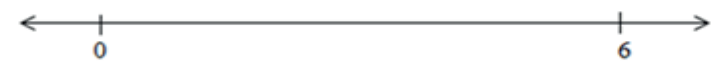

Figure 2. The second question of the fraction information test

The distribution of the responses of the students to the second question was presented in Table 4.

Table 4. Distribution of students' responses to the second question

\begin{tabular}{crrrr}
\hline \multirow{2}{*}{ Evaluation } & \multicolumn{2}{c}{$\mathrm{a}$} & \multicolumn{3}{c}{$\mathrm{b}$} \\
\cline { 2 - 5 } & $f$ & $\%$ & $f$ & $\%$ \\
\hline True & 48 & 46.15 & 33 & 31.73 \\
\hline False & 54 & 51.92 & 67 & 64.42 \\
\hline Empty & 2 & 1.92 & 4 & 3.85 \\
\hline Total & 104 & 100 & 104 & 100 \\
\hline
\end{tabular}

While $51.91 \%$ of the students answered incorrectly to item a which is about showing $2 / 3$ simple fraction on the number line, $64.42 \%$ of the students answered incorrectly to item $b$ which is about showing 9/4 compound fraction on the number line. In addition, there were also students who didn't answer this question (1.92\%, 3.85\%). The misconceptions of the students in the second question were given in Table 5 in categories.

When the answers of the students were examined, it was seen that they have misconceptions such as determination of the unit of the fraction wrongly, representation of the fraction on the number line without dividing the units, thinking compound fraction as a simple fraction and thinking fractions ...

\section{Results Related to Third Sub-problem}

The third question was about ranking of fractions. The students were asked to rank three fractions given and explain the reasons of their ranking. The third question of the test was shown in Figure 3.
Table 5. Misconceptions in the second question and sample student answers

$\begin{gathered}\text { Type of } \\ \text { Misconception }\end{gathered}$
$\begin{gathered}\text { Determination } \\ \text { of the unit } \\ \text { of fraction } \\ \text { wrongly }\end{gathered}$
$\begin{gathered}\text { Showing } \\ \text { fraction } \\ \text { dividing by } \\ \text { units }\end{gathered}$
$\begin{gathered}\text { Thinking } \\ \text { compound } \\ \text { fraction as a } \\ \text { simple fraction }\end{gathered}$

3) Order the fractions $\frac{1}{2}, \frac{3}{8}, \frac{5}{16}$ from least to greatest. Explain why you order this way.

Figure 3 . The third question of the fraction information test

The distribution of the responses of the students to the third question was presented in Table 6 .

Table 6. Distribution of students' responses to the third question

\begin{tabular}{crr}
\hline Evaluation & $f$ & \multicolumn{2}{c}{$\%$} \\
\hline True & 65 & 62.5 \\
\hline False & 39 & 37.5 \\
\hline Empty & - & - \\
\hline Total & 104 & 100
\end{tabular}

$37.5 \%$ of the students answered this question wrongly. There was no student who didn't answer the question. The misconceptions of the students in the third question were given in Table 7 in categories.

When the responses of the students were examined, it was seen that the students answered the question wrong because of reasons such as ranking according to the proximity of the numerator and denominator, ranking only by looking at the numerator or the denominator and ranking by looking at the minirity or majority of the numbers like natural numbers.

\section{Results Related to Fourth Sub-problem}

The fourth and fifth questions were about operations in fractions. In the fourth question, students were asked to find out the result of the summation operations in the models. One of the results was a simple fraction while the other was a compound fraction. The fourth question of the test was shown in Figure 4. 
Table 7. Misconceptions in the third question and sample student answers

$\begin{gathered}\text { Type of } \\ \text { Misconception }\end{gathered}$
$\begin{gathered}\text { Determination of the unit of fraction } \\ \text { wrongly }\end{gathered}$

4) The following figures represent fractions. Express the sum of these two fractions in the form of $\frac{a}{b}$

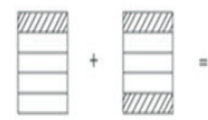

b.

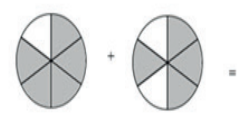

Figure 4. The fourth question of the fraction information test

The distribution of the responses of the students to the fourth question was presented in Table 8.

Table 8. Distribution of students' responses to the fourth question

\begin{tabular}{crrrr}
\hline \multirow{2}{*}{ Evaluation } & \multicolumn{1}{c}{$\mathrm{a}$} & \multicolumn{3}{c}{$\mathrm{b}$} \\
\cline { 2 - 5 } & $f$ & $\%$ & $f$ & $\%$ \\
\hline True & 82 & 78.85 & 68 & 65.38 \\
\hline False & 20 & 19.23 & 28 & 26.92 \\
\hline Empty & 2 & 1.92 & 8 & 7.69 \\
\hline Total & 104 & 100 & 104 & 100 \\
\hline
\end{tabular}

While $19.23 \%$ of the students gave wrong answer to question which is regarding the sum of simple fractions through modeling, $26.92 \%$ of the students gave wrong answer to question $b$ which is regarding the summation of the compound fractions through modeling. The misconceptions of students in the fourth question were given in Table 9 in categories.

When the responses of the students were examined, it was seen that students have misconceptions such as adding numerator with numerator, denominator with denominator; confusing the numerator with denominator and make the operation accordingly to this.

The fifth question regarding operations in fractions related to summation, multiplication and division operations in fractions. The students were asked to evaluate the given statements as true or false and to make necessary explanations. Because the summation operation is the inverse of the substraction operation and for not increasing the number of questions too much, the misconceptions at substraction operation weren't included. The fifth question of the test was shown in Figure 5.

Table 9. Misconceptions in the fourth question and sample student answers

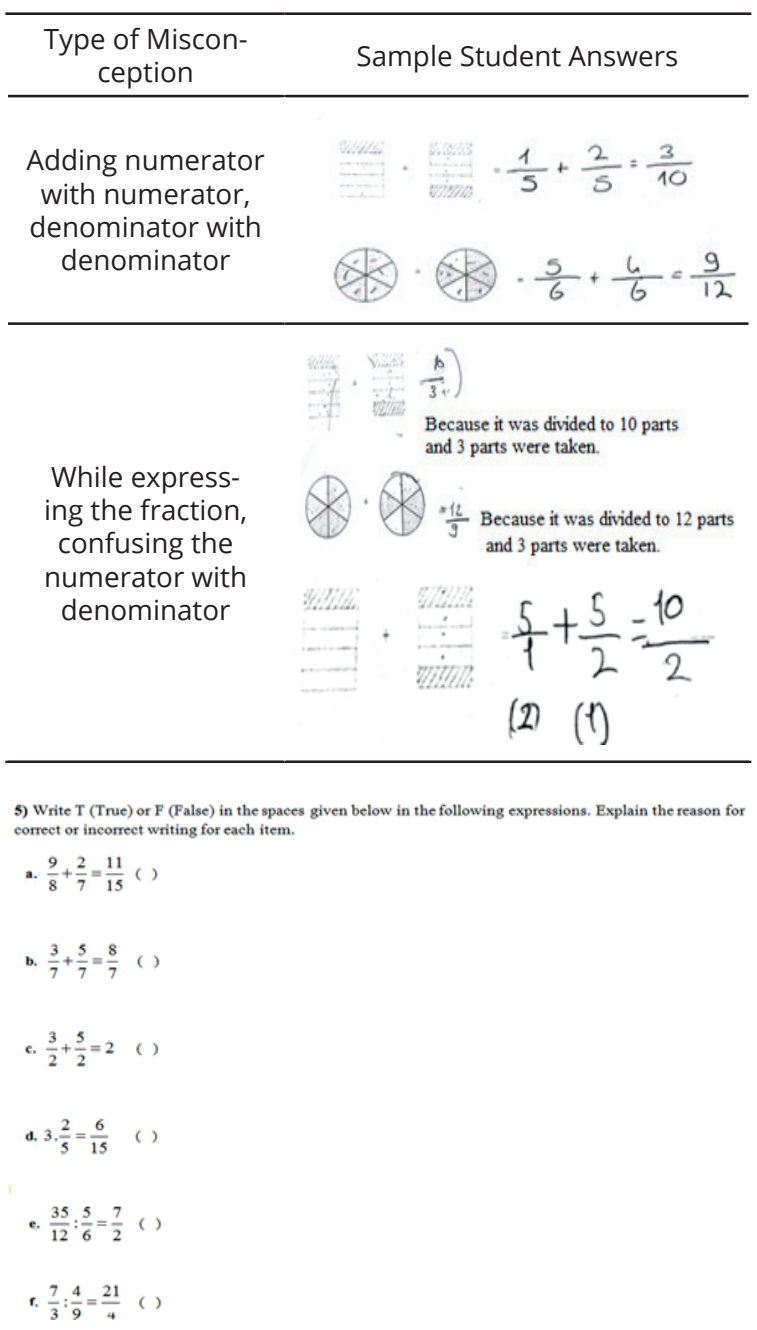

Figure 5. The fifth question of the fraction information test

The distribution of the responses of the students to the fifth question was presented in Table 10. 
Table 10. Distribution of students' responses to the fifth question

\begin{tabular}{|c|c|c|c|c|c|c|c|c|c|c|c|c|}
\hline \multirow{2}{*}{ Evaluation } & \multicolumn{2}{|l|}{ a } & \multicolumn{2}{|l|}{$b$} & \multicolumn{2}{|l|}{ C } & \multicolumn{2}{|l|}{$d$} & \multicolumn{2}{|l|}{ e } & \multicolumn{2}{|l|}{$f$} \\
\hline & $f$ & $\%$ & $f$ & $\%$ & $f$ & $\%$ & $f$ & $\%$ & $f$ & $\%$ & $f$ & $\%$ \\
\hline True & 76 & 73.08 & 86 & 82.69 & 63 & 60.58 & 47 & 45.19 & 69 & 66.35 & 42 & 40.38 \\
\hline False & 28 & 26.92 & 18 & 17.31 & 39 & 37.5 & 52 & 50 & 33 & 31.73 & 59 & 56.73 \\
\hline Empty & - & - & - & - & 2 & 1.92 & 5 & 4.81 & 2 & 1.92 & 3 & 2.88 \\
\hline Total & 104 & 100 & 104 & 100 & 104 & 100 & & & & & & \\
\hline
\end{tabular}

While $26.92 \%$ of the students answered incorrectly to item a, which is related to the adding of two fractions have different numerator and denominator; $17.31 \%$ of the students gave wrong answer to item $b$, which is related to the adding of two fractions have different numerator and same denominator. \%37.5 of the students answered incorrectly to the item c, which is related to the adding of two compound fractions have same denominators. $50 \%$ of the students responded wrongly to the item $d$, which is about multiplying an integer with a simple fraction. Lastly, the percentages of students who responded incorrectly to the $e$ and $f$ items which are about division operations in fractions were $31.73 \%$ and $56.73 \%$. The misconceptions of the students in the fifth question were given in Table 11 in categories.

Table 11. Misconceptions in the fifth question and sample student answers

\begin{tabular}{|c|c|c|}
\hline \multirow{2}{*}{$\begin{array}{c}\text { Type of Misconcep- } \\
\text { tion }\end{array}$} & \multicolumn{2}{|c|}{ Sample Student Answers } \\
\hline & $\frac{9}{8}+\frac{2}{7}=\frac{11}{15}(\mathrm{~T})$ & $\begin{array}{l}\text { Because it was found that } 11 \text { when } 9 \text { and } 2 \text { wer } \\
\text { added and } 15 \text { when } 8 \text { and } 7 \text { were added. }\end{array}$ \\
\hline $\begin{array}{l}\text { While adding two } \\
\text { fractions, adding nu- } \\
\text { merator with numer- } \\
\text { ator and denomina- } \\
\text { tor with denominator } \\
\text { separately }\end{array}$ & $\begin{array}{l}\frac{3}{7}+\frac{5}{7}=\frac{8}{7}(\mathrm{~F}) \\
\frac{3}{2}+\frac{5}{2}=2(\mathrm{~T})\end{array}$ & $\begin{array}{l}\text { Because it was found that } 8 \text { when } 3 \text { and } 5 \text { wer } \\
\text { added, and } 7 \text { when } 7 \text { and } 7 \text { were added. } 14 \\
\text { should have been found. } \\
\text { Because denominator was found } 4 \text { when } 2 \text { and } \\
2 \text { were added. Nominator was found } 8 \text { when } 5 \\
\text { and } 3 \text { were added. } \\
\qquad \frac{8}{4}=1 \frac{4}{4}=2\end{array}$ \\
\hline
\end{tabular}

Thinking multiplication of an integer with a simple fraction as conversion of an integer fraction to compound fraction

While multiplying an integer with a simple fraction, multiply the integer number with numerator and denominator separately

Equalizing the denominators while doing multiplication of fractions

\begin{tabular}{|c|c|c|}
\hline $\begin{array}{l}\text { While dividing, move } \\
\text { from the generali- } \\
\text { zation of "the first } \\
\text { fraction remains the } \\
\text { same and the second } \\
\text { fraction is inverted } \\
\text { and multiplied by the } \\
\text { first fraction" }\end{array}$ & 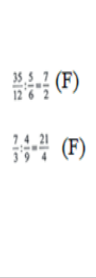 & $\begin{array}{l}\text { Because in the division operation, } \\
\text { the second fraction is inverted and } \\
\text { multiplied by the first fraction. So, it } \\
\text { is false. }\end{array}$ \\
\hline $\begin{array}{c}\text { While dividing } \\
\text { fractions, thinking } \\
\text { fractions as natural } \\
\text { numbers }\end{array}$ & \multicolumn{2}{|c|}{$\begin{array}{l}\frac{7}{3} \frac{4}{9}-\frac{21}{4} \text { (F) Because the denominator should be } \\
3 \text { when } 9 \text { divided to } 3 \text {; and the } \\
\text { nominator isn't } 27 \text { when } 7 \text { divided to } 4 .\end{array}$} \\
\hline
\end{tabular}

When we looked at the questions about adding in fractions, it was seen that the misconceptions are usually derived from adding numerator with numerator and denominator with denominator separately. We were faced with misconceptions about multiplying an integer with simple fraction such as thinking multiplication of an integer with a simple fraction as conversion of an integer fraction to compound fraction, multiplying the integer with numerator and denominator separately. The misconception about division in fractions was that "the first fraction remains the same while dividing the fractions, the second fraction is inverted and multiplied by the first fraction".

\section{Conclusion, Discussion and Recommendations}

It was seen that the causes of mistakes and the misconceptions which cause these mistakes are common. In the first question related to the part-whole relation in the fractions, it was seen that the students have misconceptions about the part-whole relation in the fractions. Although all the pieces of shapes were not equal to each other, the students expressed the fraction according to the total number of pieces dyed, and could not imagine that all parts of the fraction must be equal to each other. As shapes became more difficult, it was seen that the percentage of wrong answers increased. Looking at the studies done it was seen that, parallel to the results of this research, students didn't pay attention to the fact that parts of shapes must be equal to each other (Demiri, 2013; Haser \& Ubuz, 2002; Karaağaç \& Köse, 2015; Kocaoğlu \& Yenilmez, 2010; Okur \& Çakmak Gürel, 2016; Pesen, 2007; Reys et al., 1998). In order to eliminate this misconception, it is thought that the conceptual sub-structure of the fraction concept should be established firstly while teaching the fractions.

When the answers given to the second question related to the representation of fractions on the number line were examined, it was seen that there are four types of misconceptions. The first of these misconceptions was due to misidentifying the unit of the fraction. In the first item of this question, it was necessary to divide the number between 0 and 1 into 3 equal parts and take the second one. However, students divided the fraction into 4 parts by placing 3 lines between 0 and 1 . In a similar way, in the second item of this question, students divided each natural number into 5 parts instead of 4 parts. In Pesen's (2008) study, similar to the findings of this study, it was seen that while the students divide into equal parts the units, they place points as the number of the denominator of the fraction. Again, in the study of Bright et al. (1988), as similar to the results of this research, it seemed that the students have difficulty in separating the whole to pieces. Another misconception in this question was to show the fraction on number line without dividing to the units. When the students showed the fraction on the number line, they went 2 points from the 0 point. In the same way, when they showed the fraction, they answered the question by going 9 points from 0 point without taking into account the unit of the fraction. There were also students who point out the fraction instead of by thinking compound fraction as a simple fraction. In the study of 
Yanik et al. (2008), it was seen that there were misconceptions such as determining the unit of fraction wrongly while showing the fraction on the number line, thinking compound fraction as a simple fraction. Similar to these researchers, it was seen that in the research of Yetim and Alkan (2010), students had difficulties in showing fractions on the number line. Another misconception in this question was to show the fraction as a number between 2 and 3 by thinking the fraction as a natural number and taking into account the numbers in the numerator and denominator of fractions. When we looked at the question as a whole, it was seen that students were more likely to have difficulties in the compound fractions than in the simple fractions. In the study of Haser and Ubuz (2002), similar to the results of this study, the students were found to have difficulty in displaying the fractions on number line and they made more mistakes in the displaying of compound fractions than simple fractions. In order to avoid the misconceptions of these concepts, it is thought that it is useful to teach determining the unit of the fraction well before teaching representation of fractions on number line, to make a distinction between simple fractions and compound fractions, to teach the subject by including different modeling.

In the third question related to the ranking of the fractions, three different misconceptions were encountered. The first one was to rank by looking at the proximity of the numerator and the denominator. The students thought that the fraction is smaller if the difference between the numerator and the denominator is less. Another misconception in this question was to rank by looking at only numerator or only denominator. For example, there were students who think that if the number in the denominator is big, the fraction is small, and if it is small, the fraction is big. The third misconception was that if the number of numerator and denominator of fraction is small, then the fact is that it will be smaller. This misconception was sourced from to rank by looking at the magnitude of the numbers, thinking like a natural number. When we looked at the studies about the ranking of fractions in the literature, similar misconceptions were encountered. It was seen that in the studies of Biber, Tuna and Aktaş (2013), Hansen (2014), Mack (1990) and Önal and Yorulmaz (2017), parallel to the results of this research, students rank fractions according to the number of the fractions they contain and rank by looking at only one of the numerator and denominator. Again in the study of Okur and Çakmak Gürel (2016), it is stated that the students have misconceptions such as "the fraction is bigger when the denominator is bigger, while the numerator and denominator are expanded, only one is expanded". Similarly, in a study by Haser and Ubuz (2002), it was found that students have difficulty in ordering fractions which have unequal denominators. In order to overcome these misconceptions, it can be said that it is beneficial for teachers to teach by taking into account the students' mistakes and to use concrete materials in the teaching process.

When we looked at the fourth question about modeling and doing summation operation of simple and compound fractions, it was seen that students have misconceptions in this respect. The first one was adding numerator with numerator and denominator with denominator separately. Another misconception was that while writing the result of the addition process, to reverse the place of numerator and denominator. It was seen that there are students who write total number of pieces to numerator and total number of dyed pieces to denominator. Similarly, in a study by Kara and Incikabı (2018), it was seen that students have difficulties in modeling the summation operation in fractions.
In the fifth question concerning summation, multiplication, and division operations in fractions, it was seen that students have misconceptions about the concept. Looking at the student answers, similar to the fourth question, it was seen that the first of the misconceptions is while adding two fractions, adding the numerator with numerator and denominator with denominator separately. This misconception was due to the fact that the generalization of the processes that students learn about operations in integers to fractions, can not see fractions as two numbers' relation to each other and can not form well the concept of the equivalent fraction in their minds. It was also seen that the students made more mistakes while adding fractions which have different denominators than adding fractions which have same denominators. Parallel to the results of this research, similar misconceptions were encountered in the studies of Biber, Tuna and Aktaş (2013), Haser and Ubuz (2002), Işık and Kar (2012) and Vamvakoussi and Vosniadou (2004). In these researchers, it was mentioned that the students generalize the learned at natural numbers to the fractions. Again similar to the results of this research, in the studies of Ojose (2015), Okur and Çakmak Gürel (2016) and Önal and Yorulmaz (2017) it was seen that students have misconceptions such as collecting numerator and denominator separately when adding fractions, thinking fractions as natural numbers. In order to eliminate these mistakes, teaching of the basic concepts of fractions should be done well before operations in fractions, the concept of the equivalent fraction should be emphasized.

When the responses given to the item which is about multiplying an integer by a simple fraction were examined, it was seen that the students have misconceptions such as thinking multiplication of an integer with a simple fraction as conversion of an integer fraction to compound fraction, multiplying the integer with numerator and denominator separately and equalizing the denominators while doing multiplication of fractions. In the study of Haser and Ubuz (2002), similar to the results of this research, it was found that the students had difficulties in multiplication of a natural number with fraction. Again in the studies of Soylu and Soylu (2005) and Okur and Çakmak Gürel (2016), it was stated that the students generalize the rule of adding in fractions to multiplying of fractions and while doing multiplication in fractions equalizing the denominator as in addition in fractions. When we looked at the answers to the questions about the division in fractions, it was seen that while doing the division operation, there is a misconception moving from the generalization that "the first fraction remains the same and the second fraction is inverted and multiplied by the first fraction". Another misconcepetion was to divide the numerator with numerator and denominator with denominator separately, but while doing this operation thinking like operations in natural numbers. When we looked at the studies done in the literature, it was seen that the students have similar misconceptions about the division process in fractions. In a study of Loc, Tong, and Chau (2017), it was also stated that the students solve the division operations based on rules without considering the underlying reasoning behind the operations. Again Ma (1999) and Boaler and Humpreys (2005) stated that rule-based teaching makes it difficult to understand the subject. In order to avoid these misconceptions, it is thought that the processes performed in fractions should be presented to the students through concrete models and real-life problems, and logical reasons underlying the operations should be presented instead of giving the rules about the operations.

In the direction of this research findings, the following suggestions were given. 
- In the teaching of the subject of fractions, firstly the basic concepts related to the subject should be understood thoroughly by students, then numerical representations and operations should be taught.

- Teaching must be supported with concrete materials in order to avoid the misconceptions of the concept of fractions.

- Teaching should be done by taking into account the different meanings of fractions and different ways of fractions' representations.

\section{References}

Alacaci, C. (2014). Misconceptions of students about fractions. E. Bingölbali and M.F. Özmantar (Eds.), Mathematical difficulties encountered in primary education and solution proposals (p. 63-95). Ankara: Pegem A Publishing.

Arslan-Kılcan, S. (2006). The levels of elementary mathematics teachers' conceptual knowledge of the division with fractions. Unpublished master's thesis, Abant İzet Baysal University, Bolu.

Bezuk, N. S., \& Bieck, M. (1993). Current research on rational numbers and common fractions: Summary and implications for teachers. Research ideas for the classroom: Middle grades mathematics, 118-136.

Biber, A. Ç., Tuna, A., \& Aktaş, O. (2013). The misconceptions of the students about the fractions and the effects of these errors on the solution of fraction problems. Trakya University Journal of Education, $3(2), 152-162$.

Boaler, J., \& Humphreys, C. (2005). Connecting mathematical ideas. Portsmouth, NJ: Heineman.

Bogdan, R. C., \& Biklen, S. K. (2007). Qualitative research for education: An introduction to theory and methods. USA: Pearson Education, Inc.

Bright, G. W., Behr, M. J., Post, T. R., \& Wachsmuth, I. (1988). Identifying fractions on number lines. Journal for Research in Mathematics Education, 19(3), 215-232.

Büyüköztürk, Ş., Cakmak, E. K., Akgün, Ö. E., Karadeniz, Ş., \& Demirel, F. (2010). Scientific research methods. Ankara: Pegem Akademi.

Clarke, D. M., Roche, A., \& Mitchell, A. (2008). Ten practical tips for making fractions come alive and make sense. Mathematics Teaching in the Middle School, 13(7), 372-380.

Crouse, R.J., \& Sloyer, C.W. (1987). Mathematical questions from the classroom. Rhode Island: Janson.

Çepni, S. (2010). Introduction to research and project studies. Trabzon: Erol Ofset.

Demiri, L. (2013). Examination of information of students and teacher candidates regarding the misconceptions of students about fractions. Unpublished master's thesis, Marmara University, Istanbul.

Feagin, J. R., Orum, A. M., \& Sjoberg, G. (Eds.) (1991). A case for study. Chapel Hill, NC: University of North Carolina Press.
Fleiss, J. L. (1981). Statistical methods for rates and proportions. New York: John Wiley \& Sons Inc.

Flores, A., Samson, J., \& Yanik, H. B. (2006). Quotient and measurement interpretations of rational numbers. Teaching Children Mathematics, 13(1), 34-39.

Hansen, A. (2014). Children's errors in mathematics. London: Sage Publications.

Hart, K.M., Brown, M., Kerslake, D., Kuchemann, D., Johnson, D., Ruddock, G., \& McCartney, M. (1980). Secondary school children's understanding of mathematics. London: Chelsea College of Science and Technology.

Haser, Ç., \& Ubuz, B. (2002). Conceptual and operational performance in fractions. Education and Science, 27(126), 53-61.

Işık, C., \& Kar, T. (2012). Analyzing problems posed by 7th-grade students for addition operation with fractions. Elementary Education Online. 11(4), 10211035.

Kara, F., \& Incikabı, L. (2018). Sixth Grade Students' Skills of Using Multiple Representations in Addition and Substraction Operations in Fractions. International Electronic Journal of Elementary Education, 10(4), 463-474.

Karaağaç, M. K., \& Köse, L. (2015). Examination of information about the misconceptions of students about teacher and teacher candidates regarding the fractions. Journal of Sakarya University Faculty of Education, 30, 72-92.

Kocaoglu, T., \& Yenilmez, K. (2010). Mistakes and misconceptions of fifth-grade students in fraction problems. Dicle University Ziya Gökalp Education Faculty Journal, 14, 71-85.

Loc, N. P., Tong, D. H., \& Chau, P. T. (2017). Identifying the concept fraction of primary school students: The investigation in Vietnam. Educational Research and Reviews, 12(8), 531-539.

Ma, L. (1999). Knowing and teaching elementary mathematics. Mahwah, New Jersey: Lawrance Erlbaum.

Mack, N.K. (1990). Learning fraction with understanding: Buildingon informal knowledge. Journal for Research in Mathenıatics Education, 21(1), 13-32.

Mayer, R. E. (1987). Educational psychology: A cognitive approach. New York: Harper Collins.

McLeod, R., \& Newmarch, B. (2006). Math4life: Fractions. London, GB: Natioanal Research and Development Center for Adult Literacy and Numeracy.

Middleton, J.A., Van den Heuvel-Panhuizen, M., \& Shew, J.A. (1998). Using bar representations as a model for connecting concepts of rational number. Mathematics Teaching in the Middle School, 3(4), 302-311.

MoNE. (2013). Secondary school mathematics curriculum grades 5 to 8 . Ankara, Turkey: Author.

National Assessment of Educational Progress [NAEP]. (2007). Nations report card: Mathematics. Retrieved 
from http://www.nces.ed.gov.

National Mathematics Advisory Panel [NMP]. (2008). Foundations for success. Jessup, MD: U. S. Department of Education. Retrieved from www.ed.gov/MathPanel.

Nesher, P. (1987). Towards an instructional theory: the role of student's misconceptions. For the Learning of Mathematics, 7(3), 33-40.

Ojose, B. (2015). Students' misconceptions in mathematics: analysis of remedies and what research says. Ohio Journal of School Mathematics, 72, 30-34.

Okur, M., \& Çakmak Gürel, Z. (2016). 6th and 7th grade secondary school students' misconceptions about fractions. Erzincan University Education Faculty Journal, 18(2), 922-952.

Olkun S., \& Toluk-Uçar Z. (2007). Activity-based mathematics teaching in primary education. Ankara: Maya Akademi Publishing Distribution.

Önal, H., \& Yorulmaz, A. (2017). The errors made by primary school fourth graders on fractions. Journal of Research in Education and Society, 4(1), 98-113.

Pesen, C. (2007). Misconceptions of students about fractions. Education and Science, 32(143), 79-88.

Pesen, C. (2008). Students' learning difficulties and misconceptions in pointıng the fractions on the number line. Inonu University Journal of Education, 9(15), 157-168.

Reys, R. E., Suydam, M.N., Lindquist, M.M, \& Smith, N.L. (1998). Helping Children Learn Mathematics. Boston: Allyn and Bacon.

Smith, J. P., diSessa, A. A., \& Roschelle, J. (1993). Misconceptions reconceived: A constructivist analysis of knowledge in transition. The Journal of Learning Sciences, 3(2), 115-163.

Stafylidou, S., \& Vosniadou, S. (2004). The development of students' understanding of the numerical value of fractions. Learning and instruction, 14(5), 503-518.

Soylu, Y., \& Soylu, C. (2005). Learning difficulties of $5 \mathrm{fh}$ class in primary education at fraction: Ordering, adding, subtraction, multiplication in fraction and problems related to fraction. Erzincan Education Faculty Journal, 7(2), 101-117.

Şiap, I., \& Duru, A. (2004). The ability to use geometric models in fractions. Gazi University Kastamonu Education Journal, 12(1), 89-96.

Taşkın, D., \& Yıldız, C. (2011, April). Developing materials appropriate for common knowledge construction modeling for teaching of addition and subtraction in fractions. Oral presentation presented at the International Conference on New Trends in Education and Their Implications congress Antalya-Turkey.

Usiskin, Z. (2007). The arıthmetıc operatıons as mathematıcal models. Modelling and Applications in Mathematics Education, 257.

Vamvakoussi, X., \& Vosniadou, S. (2004). Understanding the structure of the set of rational numbers: A con- ceptual change approach. Learning and Instruction, 14(5), 453-467.

Van De Walle, J. A., Karp, K. S., \& Bay-Williams, J. M. (2012). Elementary and secondary school mathematics: Teaching with developmental approach. (S. Durmuş, Trans.) Ankara: Nobel Academic Publishing.

Yanik, H. B., Helding, B., \& Flores, A. (2008). Teaching the concept of unit in measurement interpretation of rational numbers. Elementary Online, 7(3), 693-705.

Yetim, S., \& Alkan R. (2010). Common mistakes and misconceptions of 7 th grade students about the rational numbers and placement of the rational numbers on the number line. Kyrgyzstan- Turkey Manas University Journal of Science, 2(11), 87-109.

Yılmaz, Z., \& Yenilmez, K. (2007). Misconceptions of 7th and 8th grade primary school students on decimal numbers. Afyon Kocatepe University Journal of Science, 8(1), 269-290.

Zembat, İ. Ö. (2008). What is misconception? M. F. Özmantar, E. Bingölbali and H. Akkoç (Eds.), Mathematical misconceptions and solution proposals (p. 1-8) Ankara: PegemA Publishing. 